\title{
Níveis séricos e imunoexpressão tecidual do marcador CA 19-9 no carcinoma colorretal e comprometimento linfonodal
}

\author{
Serum levels and tissue immunoexpression of CA 19-9 marker in \\ colorectal carcinoma and lymph node involvement
}

Mariane Martins Manso', Newton Eiji Kitamura², José Roberto Martins de Souza3 ${ }^{3}$, José Eduardo Gonçalves³, Leandro Luongo Matos ${ }^{4}$, Ana Maria Amaral Antonio Mader ${ }^{5}$, Vera Luiza Capelozzi ${ }^{6}$, Jaques Waisberg ${ }^{1,3}$

\section{Resumo}

Introdução: 0 carcinoma colorretal é uma das neoplasias mais incidentes nos países ocidentais. É controverso se os níveis séricos e a imunoexpressão tecidual do marcador tumoral CA 19-9 estão relacionados com o comprometimento linfonodal e com a invasão linfática no carcinoma colorretal. Casuística e métodos: Em 45 pacientes com carcinoma colorretal operados, o nível de CA19-9 pré-operatório e a imunoexpressão do CA19-9 no tecido neoplásico foram analisados. Valores de CA19-9 $\geq 37 \mathrm{Ul} / \mathrm{ml}$ foram considerados aumentados. As amostras do tecido com carcinoma colorretal foram submetidas ao estudo imunoistoquímico, com anticorpo monoclonal anti-CA19-9. A intensidade de expressão do CA19-9 na neoplasia foi semiquantificada em leve $(+/+++)$, moderada $(++/+++)$, intensa $(+++/+++)$ ou ausente. Foram comparados os níveis séricos e a imunoexpressão tecidual do marcador CA19-9 com 0 comprometimento linfonodal e a invasão linfática. Resultados: 0 nível sérico e a imunoexpressão tecidual do CA19-9 não se relacionaram significantemente com o comprometimento linfonodal ( $p=0,49$ e $p=0,45$, respectivamente) ou com a invasão linfática ( $p=0,12$ e $p=0,74$, respectivamente). Conclusões: 0 nível sérico e a imunoexpressão tecidual do CA19-9 não refletem o comprometimento linfonodal e a presença de invasão linfática no carcinoma colorretal.

Palavras-chave: Carcinoma; neoplasias colorretais; marcadores biológicos de tumor; imunoistoquímica; prognóstico.

\section{Abstract}

Introduction: Colorectal carcinoma is one of the most common tumors in Western countries. It is controversial whether serum and tissue immunohistochemical expression of tumor marker CA 19-9 are associated with lymph node involvement or lymphatic invasion in colorectal carcinoma. Methods: In 45 patients with colorectal carcinoma operated, the preoperative serum levels and immunoexpression of CA19-9 in tumor tissues were performed. Values of CA19-9 $\geq 37 \mathrm{UI} / \mathrm{ml}$ were considered increased. Tissue samples with colorectal carcinoma were subjected to the immunohistochemistry study, with monoclonal antibody anti-CA19-9. The severity of CA19-9 expression in the tumor was semiquantified as mild $(+/+++)$, moderate $(++/+++)$, intense $(+++/+++)$, or absent. We compared the serum levels and the tissue immunoexpression of CA19-9 marker with lymph node and lymphatic invasion. Results: Serum level and tissue immunoexpression of CA19-9 did not correlate significantly with lymph node involvement $(p=0.49$ and $p=0.45$, respectively) or with lymphatic invasion ( $p=0.12$ and $p=0.74$, respectively). Conclusions: The serum level and tissue immunoexpression of CA19-9 do not reflect the presence of lymph node involvement and the presence of lymphatic invasion in colorectal carcinoma.

Keywords: Carcinoma; colorectal neoplasms; tumor markers, biological; immunohistochemistry; prognosis.

Recebido: 3/11/2010

Revisado: 20/2/2011

Aprovado: $14 / 3 / 2011$

Trabalho realizado com apoio do Programa Institucional de Bolsas de Iniciação Científica do Conselho Nacional de Desenvolvimento Científico e Tecnológico (PIBIC $\mathrm{CNPq}$ )

Disciplina de Cirurgia do Aparelho Digestivo da Faculdade de Medicina do ABC (FMABC), Santo André (SP), Brasil

2 Faculdade de Medicina da Universidade Cidade de São Paulo (Unicid), São Paulo (SP), Brasil

Serviço de Gastroenterologia Cirúrgica do Hospital do Servidor Público Estadual de São Paulo, São Paulo (SP), Brasil

${ }^{4}$ Departamento de Cirurgia da FMABC, Santo André (SP), Brasil

5 Disciplina de Patologia Geral da FMABC, Santo André (SP), Brasil

6 Departamento de Patologia da Faculdade de Medicina da Universidade de São Paulo (USP), São Paulo (SP), Brasil

Endereço para correspondência: Jaques Waisberg - Rua das Figueiras, 550 - apto. 134 - Bairro Jardim - CEP: $09080-300$ - Santo André (SP) - E-mail: jaqueswaisberg@uol.com.br 


\section{Introdução}

Nos países ocidentais, inclusive no Brasil, o carcinoma colorretal é uma das neoplasias mais frequentes do trato gastrintestinal. É considerado o terceiro carcinoma mais frequente no mundo e o segundo, em países desenvolvidos ${ }^{1-3}$.

O estadiamento da neoplasia colorretal, de acordo com a Classificação de Tumores Malignos (TNM), é, ainda, o fator prognóstico mais consistente ${ }^{4}$. Entretanto, a informação prognóstica fornecida pelo estadiamento TNM não é, habitualmente, disponível no pré-operatório. Um fator prognóstico seguro pode ser de importante valor clínico na terapia neoadjuvante planejada nesses pacientes.

O CA 19-9 foi identificado por Koprowski et al. ${ }^{5}$. Esse antígeno carboidrato citosólico é uma lacto- $\mathrm{N}$-fucopentose sializada, proteína da família das mucinas, relacionada com o antígeno monosializado do grupo sanguíneo Lewis ${ }^{\text {a }}$, que se expressa sobre a membrana celular e no citosol de células de carcinomas ${ }^{6}$. É sintetizado normalmente pelas células dos ductos pancreáticos e pelos epitélios cólico, gástrico, da vesícula biliar, endometrial e salivar ${ }^{7,8}$.

$\mathrm{O}$ interesse na expressão do antígeno Lewis ${ }^{\mathrm{a}}$ em tecidos normais e em tumores ocorre porque este derivado sializado dos antígenos Lewis pode atuar como marcador associado a tumores de neoplasias gastrintestinais ${ }^{9}, 10$. O nível sérico deste marcador pode aumentar nos carcinomas das vias biliares, estômago, fígado, mama e intestino grosso 7,11 .

O conteúdo de CA19-9 aumenta de forma progressiva a partir dos níveis encontrados na mucosa cólica, no adenoma e no carcinoma colorretal, sugerindo a utilidade do seu nível sérico para avaliar o grau de progressão da neoplasia, do radicalismo da operação ou a detecção da sua recidiva ${ }^{8,12-14}$.

O CA19-9 tecidual foi associado à maior incidência de acometimento linfonodal, invasão linfática ${ }^{15}$ e metástases ${ }^{16,17}$, enquanto outros autores não identificaram esta relação ${ }^{18-20}$.

O objetivo deste estudo foi analisar a relação entre os níveis séricos pré-operatórios do CA19-9 e sua imunoexpressão tecidual com o comprometimento linfonodal e com a invasão linfática, no carcinoma colorretal.

\section{Casuística e métodos}

Este estudo foi aprovado pelo Comitê de Ética em Pesquisa (CEP) do Hospital do Servidor Público Estadual de São Paulo (IAMSPE) e registrado sob o número 104/07.

As informações clínicas e morfológicas foram obtidas por meio de consultas em prontuários hospitalares ou por entrevista com os pacientes ou familiares nos retornos ambulatoriais.

Neste estudo, foram considerados critérios de inclusão pacientes adultos com carcinoma colorretal, confirmado pelo estudo histopatológico da lesão extirpada com intenção curativa (ausência de metástases não-ressecáveis, retirada de, pelo menos 12 linfonodos e ausência de margens comprometidas na peça cirúrgica). Foram considerados critérios de exclusão pacientes menores de 18 anos de idade, enfermos submetidos à operação de urgência e submetidos à neoadjuvância para tratamento da neoplasia colorretal.

No período de outubro de 2006 a janeiro de 2008, foram estudados 45 pacientes consecutivos com carcinoma colorretal operados com intenção curativa no Serviço de Gastroenterologia Cirúrgica do Hospital do Servidor Público Estadual de São Paulo.

A média de idade dos pacientes estudados foi de 69,53 \pm 12,37 anos (41 a 91 anos), sendo $23(51,1 \%)$ do sexo masculino e 22 $(48,9 \%)$ do sexo feminino.

O estadiamento foi realizado pelo exame clínico e proctológico completos; determinação sérica do CA19-9; colonoscopia com biópsia da lesão e respectivo estudo histopatológico; enema opaco, quando indicado; radiografia do tórax; tomografia computadorizada de abdome total e ultrassonografia abdominal. A classificação do estadiamento clínico-patológico adotada foi a TNM $2002^{21}$.

Para a coleta do CA19-9 sérico, os enfermos foram submetidos à punção da veia cefálica do membro não-dominante imediatamente antes do início da operação. As amostras de sangue foram encaminhadas de forma imediata para mensuração dos níveis séricos de CA19-9. Adotou-se o nível de corte (cut-off) para o CA19-9 $\geq 37 \mathrm{UI} / \mathrm{ml}^{22,23}$.

Dos 45 pacientes, em 29 (64,4\%), a neoplasia estava localizada no cólon: 2 no ceco, 7 no cólon ascendente, 2 no cólon transverso, 2 no cólon descendente e 14 no sigmoide, além de 2 pacientes com neoplasia sincrônica, uma delas envolvendo sigmoide e cólon transverso e outra envolvendo sigmoide e cólon ascendente. Em 16 (35,6\%) enfermos, a neoplasia estava localizada no reto. Vinte e oito $(62,2 \%)$ pacientes apresentaram lesão com diâmetro $<5,0 \mathrm{~cm}$ e em 17 (37,8\%), o diâmetro foi $\geq 5,0 \mathrm{~cm}$ (Tabela 1). A média do número de linfonodos extirpados dos 45 pacientes foi de 17,4 por peça operatória. Houve acometimento pelo carcinoma colorretal dos linfonodos extirpados em 22 (48,9\%) pacientes. Em outros 23 (51,1\%), os linfonodos da peça operatória estavam livres de acometimento neoplásico.

Para a realização do estudo histopatológico, todos os espécimes cirúrgicos, previamente fixados em solução de formol a $10 \%$, foram incluídos em blocos de parafina. Três cortes de $4,0 \mu \mathrm{m}$ foram obtidos de cada bloco na periferia do tumor para obtenção de áreas com e sem tumor, sendo corados pela técnica de hematoxilina-eosina (HE) para diagnóstico anatomopatológico e avaliação do grau de invasão da parede cólica e do grau de diferenciação celular. A verificação de comprometimento neoplásico dos linfonodos ressecados foi realizada por meio de cortes corados por HE.

Para a realização do estudo imunoistoquímico, todos os espécimes previamente fixados em formol e incluídos em blocos de parafina foram submetidos a dois cortes adicionais de $4 \mu \mathrm{m}$, depositados em lâminas previamente silanizadas. As lâminas foram desparafinadas por três banhos sucessivos de cinco minutos de xilol e três banhos em etanol abso- 
luto. A seguir, foram acondicionadas em recipiente próprio e submersas em solução tampão fosfato de sódio $0,05 \mathrm{M} \mathrm{e} \mathrm{pH} \mathrm{=} \mathrm{7,2} \mathrm{(PBS)} \mathrm{por} \mathrm{dez}$ minutos. Foi realizado bloqueio das peroxidases endógenas pelo gotejamento de peróxido de hidrogênio $30 \mathrm{~V}$ a 3\%, em câmara úmida, à temperatura ambiente durante 10 minutos, seguido de mais uma lavagem com PBS por 10 minutos. Terminada esta etapa, realizou-se a recuperação antigênica. As lâminas foram acondicionadas em cuba com solução de citrato $10 \mathrm{mM}, \mathrm{pH}=6,0$, e submetidas ao calor em banho-maria em temperatura de $35^{\circ} \mathrm{C}$ por período de 40 minutos e, ao final deste processo, foram deixadas para esfriar por 20 minutos em temperatura ambiente, sendo realizada lavagem com PBS por cinco minutos.

As lâminas foram incubadas com anticorpo específico anti-CA19-9 (GI-MA ${ }^{\circledR}$, clone L2KGI2, Siemens Healthcare Diagnostics Products Ltd.,
United Kingdom), diluído em albumina bovina (Sigma ${ }^{\circledR}$ ) durante 16 a 18 horas a $4^{\circ} \mathrm{C}$. Em seguida, foram lavadas em tampão PBS, com três trocas de três a cinco minutos, e incubadas com anticorpo secundário biotinilado (anti-IG) $\left(\right.$ Dako $^{\circledR}$ ) diluído em albumina bovina durante 30 minutos à temperatura ambiente. Seguiram-se as etapas: lavagem em tampão PBS com três trocas de cinco minutos cada; incubação com o complexo ABC (StretABC-HRP ${ }^{\circledR}$ ) diluído em tampão Tris, durante 30 minutos à temperatura ambiente; lavagem em tampão PBS com três trocas de três a cinco minutos cada; revelação com solução de diaminobenzidina (DAB) $\left(\right.$ Sigma $\left.^{\circledR}\right)$ a $0,6 \%$ e peróxido de hidrogênio de $0,06 \%$. As lâminas foram lavadas em água corrente e destilada, e contracoradas com hematoxilina de Harris por um minuto, e novamente lavadas em água corrente e destilada.

Tabela 1 - Valores dos níveis séricos normal $(<37 \mathrm{Ul} / \mathrm{ml}$ ) e elevado ( $\geq 37 \mathrm{Ul} / \mathrm{ml}$ ) do CA19-9 comparados com as variáveis morfológicas em pacientes operados de carcinoma colorretal

\begin{tabular}{|c|c|c|c|c|c|}
\hline & \multicolumn{2}{|c|}{ CA19-9 < $37 \mathrm{Ul} / \mathrm{ml}(\mathrm{n}=35)$} & \multicolumn{2}{|c|}{$\mathrm{CA} 19-9 \geq 37 \mathrm{UI} / \mathrm{ml}(\mathrm{n}=10)$} & $\mathrm{p}$ \\
\hline Local & Cólon $=23(65,7 \%)$ & Reto $=12(34,3 \%)$ & Cólon $=6(60,0 \%)$ & Reto $=4(40,0 \%)$ & 0,72 \\
\hline Linfonodos Acometidos & Não $=19(54,3 \%)$ & $\operatorname{Sim}=16(45,7 \%)$ & Não $=4(40,0 \%)$ & $\operatorname{Sim}=6(60,0 \%)$ & 0,49 \\
\hline Invasão vascular/linfática & Não $=24(68,6 \%)$ & $\operatorname{Sim}=11(31,4 \%)$ & Não $=5(50,0 \%)$ & $\operatorname{Sim}=5(50,0 \%)$ & 0,45 \\
\hline Imunoexpressão do CA 19-9 & $0 /+=16(45,7 \%)$ & $++/+++=19(54,3 \%)$ & $0 /+=1(10,0 \%)$ & $++/+++=9(90,0 \%)$ & 0,06 \\
\hline
\end{tabular}

UI: unidades internacionais; $n$ : número de pacientes; M: masculino; F: feminino; 0: ausência de expressão; + : expressão leve; ++ : expressão moderada; +++ : expressão intensa. Teste de Mann-Whitney.

Tabela 2 - Relação entre a imunoexpressão do marcador CA19-9 no tecido neoplásico e as variáveis morfológicas dos pacientes operados de carcinoma colorretal

\begin{tabular}{|c|c|c|c|c|c|}
\hline \multirow[b]{3}{*}{ Local } & \multicolumn{4}{|c|}{ CA 19-9 - Imunoexpressão tecidual } & \multirow{3}{*}{$\begin{array}{c}p \\
0,99\end{array}$} \\
\hline & \multicolumn{2}{|c|}{$0 /+(n=17)$} & \multicolumn{2}{|c|}{$++/+++(\mathrm{n}=28)$} & \\
\hline & Cólon = $11(64,7 \%)$ & Reto $=6(35,3 \%)$ & Cólon = 18 (64,3\%) & Reto $=10(35,7 \%)$ & \\
\hline Linfonodos Acometidos & Não $=6(35,3 \%)$ & $\operatorname{Sim}=11(64,7 \%)$ & Não $=17(60,7 \%)$ & $\operatorname{Sim}=11(39,3 \%)$ & 0,12 \\
\hline Invasão Vascular/ linfática & Não $=10(58,8 \%)$ & $\operatorname{Sim}=7(41,2 \%)$ & Não $=19(67,9 \%)$ & $\operatorname{Sim}=9(32,1 \%)$ & 0,74 \\
\hline CA $19-9$ sérico (UI/ml) & $<37(\mathrm{n}=16)(94,1 \%)$ & $\geq 37(n=1)(5,9 \%)$ & $<37(n=19)(67,9 \%)$ & $\geq 37(n=9)(32,1 \%)$ & 0,06 \\
\hline
\end{tabular}

0: ausência de expressão; +: expressão leve; ++: expressão moderada; +++: expressão intensa; n: número de pacientes; UI: unidades internacionais; M: masculino; F: feminino. Teste de Mann-Whitney.

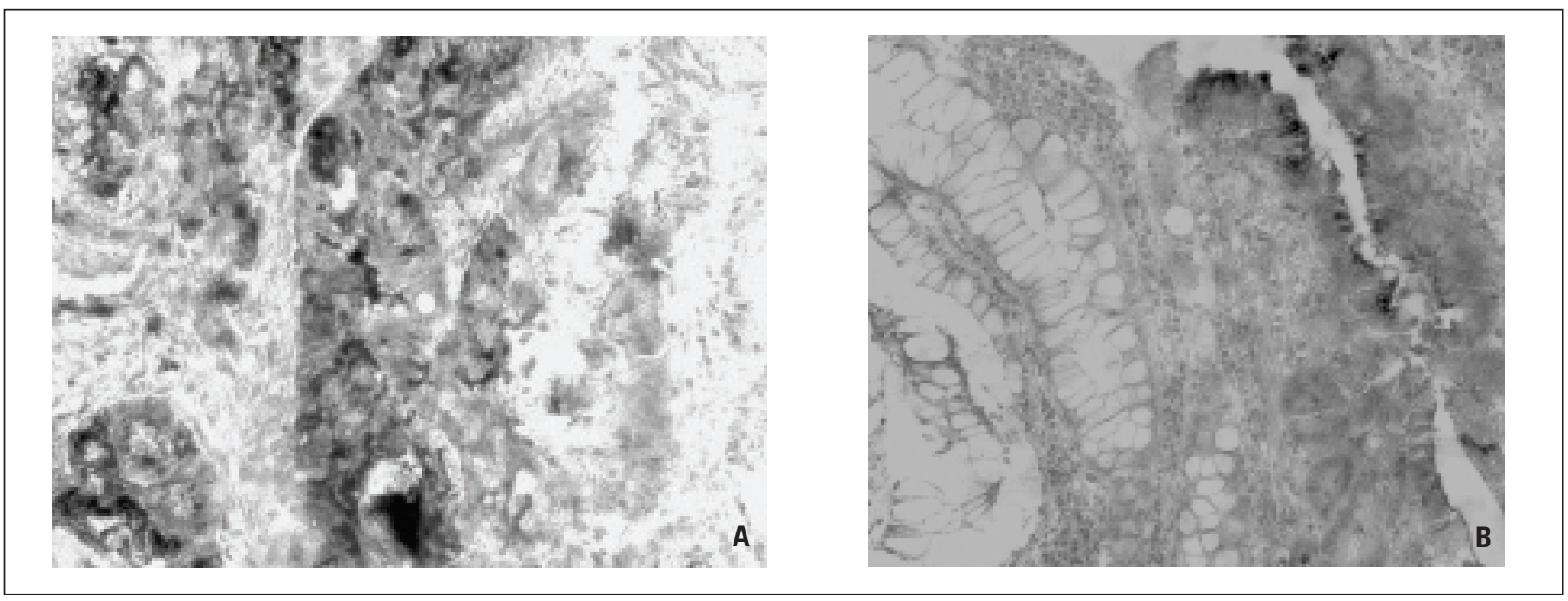

Figura 1 - Fotomicrografia de imunoexpressão positiva representada pelo colorido acastanhado no citoplasma das células neoplásicas do carcinoma colorretal (imunoistoquímica com anticorpo anti-CA19-9, aumento de 200x). 
A análise microscópica das lâminas foi realizada com o auxílio de microscópio óptico comum, com lente objetiva de 100x e magnificação final de 200x. A leitura de todas as lâminas foi sempre realizada por patologista experiente na interpretação imunoistoquímica.

A reação foi considerada positiva quando a expressão ocorreu de modo difuso, com distribuição homogênea. Os controles positivos foram cortes do centro germinativo de tonsila normal. Nas lâminas usadas como controle negativo, subtraiu-se o anticorpo primário da reação.

A intensidade de expressão do CA 19-9 nas áreas neoplásicas foi semi quantificada em áreas representativas da neoplasia como leve $(+/+++)$, moderada $(++/+++)$, intensa $(+++/+++)$ e ausente. Áreas de diferentes graus de diferenciação celular foram avaliadas em varredura, sempre que presentes nas lâminas (Figura 1).

O nível de significância adotado foi de $5 \%(\mathrm{p} \leq 0,05)$. Foram realizados cálculos paramétricos e não-paramétricos, de acordo com a natureza das variáveis e o n de cada grupo estudado. Os modelos utilizados foram: média aritmética e respectivo desvio padrão; cálculo de percentuais; teste do $t$ não-pareado ( $t$ de Student); teste não-paramétrico da soma por postos (Mann-Whitney) e teste exato de Fisher. O programa estatístico utilizado foi o SPSS for Windows 16.0 (SPSS Inc., USA).

\section{Resultados}

O valor médio do CA19-9 sérico foi de 120,5 $\pm 40,6 \mathrm{UI} / \mathrm{mL}$. Em $10(22,2 \%)$ pacientes foram encontrados valores elevados ( $\geq 37,0 \mathrm{UI} /$ $\mathrm{mL}$ ) de CA19-9 sérico (Tabela 1). Nestes pacientes, seis (60\%) apresentaram neoplasias de cólon e quatro (40\%) neoplasias do reto (Tabela 1). Todos os pacientes, com imunoexpressão do CA19-9 tecidual ausente, apresentavam níveis normais de CA19-9 sérico.

Em relação à imunoexpressão do CA19-9 no tecido neoplásico colorretal, cinco $(11,1 \%)$ pacientes apresentavam imunoexpressão ausente e, neles, o valor médio do CA19-9 foi de 2,8 \pm 2,9 UI/mL. Em $12(26,7 \%)$ pacientes, a imunoexpressão foi considerada leve e o valor médio do CA19-9 foi de 11,1 $\pm 11,1 \mathrm{UI} / \mathrm{mL}$. Em 17 (37,8\%) pacientes, a imunoexpressão foi moderada e o valor médio do CA19-9 foi de 167,3 $\pm 54,1 \mathrm{UI} / \mathrm{ml}$. Em outros $11(24,4 \%)$ pacientes, a imunoexpressão foi intensa e o valor médio do CA19-9 foi de 221,0 $\pm 21,6 \mathrm{UI} / \mathrm{mL}$. Nos pacientes com neoplasia de cólon, a imunoexpressão do CA19-9 no tecido neoplásico foi a seguinte: em $4(13,8 \%)$ pacientes foi ausente; em 7 (24,1\%) foi leve; em 11 (38,0\%) foi moderada e em outros 7 (24,1\%) foi intensa. Nas neoplasias de reto, a imunoexpressão do CA19-9 foi ausente em um (6,3\%) paciente; leve em cinco $(31,2 \%)$; moderada em seis $(37,5 \%)$ e intensa em quatro $(25,0 \%)$.

Vinte e três $(51,1 \%)$ pacientes tinham linfonodos comprometidos e, em 22 (48,8\%), os linfonodos estavam livres de invasão pelo carcinoma colorretal (Tabelas 1 e 2). Nos pacientes com linfonodos infiltrados pela neoplasia, o valor médio do CA19-9 sérico foi de 138,0 \pm 53,4 UI/ $\mathrm{mL}$. Nos pacientes sem linfonodos infiltrados pela neoplasia, o valor médio do CA19-9 sérico foi de 103,8 \pm 68,8 UI/mL. Não se observou diferença significante $(\mathrm{p}=0,49)$ em relação à presença de linfonodos acometidos e à elevação do nível sérico do CA19-9 (Tabela 1).

Em 17 (37,8\%) pacientes havia invasão vascular linfática constatada no exame anatomopatológico da peça extirpada, enquanto que, em 28 (62,2\%) enfermos, não foi verificada invasão vascular linfática (Tabelas 1 e 2). Nos pacientes com invasão vascular linfática pelo carcinoma colorretal, o valor médio do CA19-9 sérico foi de 184,3 $\pm 60,5$ $\mathrm{UI} / \mathrm{mL}$. Nos enfermos sem invasão vascular linfática, o valor médio do CA19-9 sérico foi de 85,3 \pm 39,0 UI/mL. A presença de invasão vascular linfática não apresentou relação significante com o aumento do CA19-9 ( $\mathrm{p}=0,45)$ (Tabela 1).

A imunoexpressão do CA19-9 no tecido neoplásico nos pacientes com linfonodos infiltrados pela neoplasia se apresentou ausente em 4 (18,2\%) pacientes; leve em 7 (31,8\%); moderada em 5 $(22,7 \%)$ e intensa em 6 (27,3\%). A imunoexpressão do CA19-9 no tecido neoplásico nos pacientes sem invasão linfonodal apresentouse ausente em $1(4,4 \%)$, leve em $5(21,7 \%)$, moderada em 12 (52,2\%) e intensa em outros $5(21,7 \%)$. A intensidade da imunoexpressão do CA19-9 não apresentou relação com a presença de linfonodos acometidos $(\mathrm{p}=0,12)$ (Tabela 2).

A imunoexpressão do CA19-9 no tecido neoplásico nos pacientes com invasão linfática pelo carcinoma colorretal foi a seguinte: em 3 (18,7\%) foi ausente; em 4 (25,0\%), leve; em 3 (18,8\%), moderada e em $6(37,5 \%)$, intensa. Nos pacientes sem invasão linfática, a imunoexpressão do CA19-9 no tecido neoplásico nestes pacientes foi a seguinte: em 2 (6,9\%), ausente; em 8 (27,6\%), leve; em 14 (48,3\%), moderada e em 5 (17,2\%), intensa. A intensidade da imunoexpressão do CA19-9 não apresentou relação com a invasão vascular linfática $(\mathrm{p}=0,74)($ Tabela 2$)$.

\section{Discussão}

O CA19-9 sérico e, mais recentemente, a imunoexpressão do CA19-9 no tecido de carcinomas colorretais foram estudados para auxiliar a estimativa de prognóstico e para correlacioná-los com os aspectos morfológicos da neoplasia com intuito de orientar a programação do tratamento de cada paciente ${ }^{24-27}$.

Nakayama et al. ${ }^{15}$ não encontraram pacientes com CA19-9 elevado quando a imunoexpressão do CA19-9 tecidual foi ausente, e semelhante resultado foi encontrado no presente estudo. Nakayama et al. ${ }^{15,24}$ observaram que os níveis séricos médios do antígeno CA19-9 aumentaram de acordo com a intensidade da expressão imunoistoquímica do CA19-9, no tecido neoplásico colorretal.

Ueda, Shimada e Urakawa ${ }^{23}$ examinaram o significado clínico dos níveis séricos pré-operatórios de CA19-9 em 206 pacientes com carcinoma colorretal operado. Em 52 (25,2\%) pacientes, o nível sérico do CA19-9 estava aumentado $(>37 \mathrm{U} / \mathrm{mL})$ antes do tratamento cirúrgico. Todos estes pacientes com CA19-9 aumentado tinham carcinoma avançado e incidências significantemente elevadas (91,3\%) de 
invasão do tumor na musculatura própria e de envolvimento linfático (54,5\%). Esses autores notaram que a incidência de metástases hepáticas e de doença avançada no grupo de pacientes, com níveis elevados de CA19-9, era significantemente mais elevada do que aquelas no grupo de CA19-9 normal (38,5 versus $6,5 \%$ e 42,9 versus $14,8 \%$, respectivamente). A sobrevivência de longo prazo do grupo com nível sérico elevado de CA19-9 foi significantemente pior $(\mathrm{p}<0,0001)$ do que aquela dos pacientes do grupo com nível sérico normal de CA19-9. Os autores concluíram que o nível sérico elevado do CA19-9 no pré-operatório é indicador útil da presença de metástases hepáticas e de pior prognóstico, nos pacientes com carcinoma colorretal. No presente estudo, o CA19-9 sérico estava aumentado em dez (22,2\%) pacientes; o nível sérico médio foi de 120,5 $\pm 440,6 \mathrm{UI} / \mathrm{mL}$.

Em relação à localização do carcinoma colorretal, Nozoe et al. ${ }^{20}$ encontraram, nas neoplasias de reto, níveis séricos mais elevados, porém não-significantes $(\mathrm{p}=0,47)$ de CA19-9. $\mathrm{Na}$ atual série, também não foram encontrados valores maiores do CA19-9 sérico no reto. Esta diferença de níveis séricos do CA19-9 entre o cólon e reto poderia ser explicada devido à presença de lesões mais infiltrativas no reto, e pelo fato da drenagem retal poder ocorrer pelos sistemas porta e cava inferior e a drenagem do cólon ser praticamente exclusivamente portal. Nakayama et $a l .{ }^{24}$ e Akamine et al. ${ }^{28}$ não encontraram relação significante da localização da neoplasia com a imunoexpressão tecidual do CA19-9, resultados concordantes com os do presente estudo.

No presente estudo não foi encontrada relação significante entre o nível sérico elevado do CA19-9 e o acometimento linfonodal, resultado semelhante ao encontrado por Sasaki et al. ${ }^{29}$. Porém, outros autores ${ }^{20,30}$ encontraram maior acometimento de linfonodos em pacientes com CA19-9 sérico elevado. Nakayama et al. ${ }^{15}$ encontraram correlação significante $(\mathrm{p}<0,01)$ da imunoexpressão tecidual CA19-9 com a presença de linfonodos acometidos. No presente estudo, esta relação não foi significante, assim como a presença de invasão linfática microscópica.

A razão pela qual os pacientes com câncer colorretal avançado apresentam níveis mais elevados séricos de CA19-9 ainda não está completamente esclarecida. Takada et al. ${ }^{31}$ relataram que o antígeno CA19-9 serve como ligante específico para a molécula de adesão en- dotelial de leucócito (ELAM-1), o que pode ajudar as células tumorais na adesão às células circulantes e, consequentemente, iniciar o processo metastático. O antígeno CA19-9 pode estar envolvido no processo de angiogênese tumoral, influenciando o rápido crescimento do tumor e das metástases. Esta pode ser uma das razões principais devido a qual os casos com níveis séricos mais elevados de CA19-9 mostraram frequência maior de metástases e, consequentemente, pior prognóstico ${ }^{23}$.

No tocante à imunoexpressão do tecido neoplásico do CA19-9, a detecção e a quantificação de um marcador com diferentes reagentes podem não produzir resultados idênticos, mesmo que estes reagentes sejam utilizados em formatos similares do ensaio ${ }^{32}$. A comparação de resultados entre análises separadas poderia conduzir a conclusões bastante diferentes, o que pode explicar os resultados aparentemente discrepantes observados na literatura.

Na presente série, as amostras foram coletadas de peças operatórias de carcinomas colorretais com confirmação histopatológica previamente à operação. Muitos ensaios de marcador tumoral, especialmente aqueles que são baseados em reações antígeno-anticorpo, são muito mais sensíveis em espécimes frescos ou congelados. Em tecidos fixados, a "sobrevivência" do antígeno pode variar de acordo com os diferentes fixadores. Os ensaios podem ser influenciados não só pelo fixador ou tipos de anticoagulantes utilizados na preparação da lâmina, mas também pelas condições de armazenamento, bem como pela duração do armazenamento. Para muitos marcadores solúveis, ciclos de congelamento e descongelamento múltiplos podem diminuir a reatividade das células, dependendo do ensaio específico. Mesmo que os métodos de coleta e armazenamento sejam padronizados, as diferenças de amostragem podem alterar substancialmente os resultados ${ }^{32}$.

Nas condições deste estudo, os resultados obtidos mostraram que os níveis séricos pré-operatórios e a imunoexpressão tecidual do marcador CA19-9 no carcinoma colorretal não mostraram relação com o comprometimento linfonodal e com a invasão linfática. O nível sérico e a imunoexpressão tecidual do CA19-9 no carcinoma colorretal não refletem o comprometimento linfonodal e a presença de invasão linfática no carcinoma colorretal. Casuísticas com maior número de pacientes poderão confirmar os resultados obtidos no presente estudo.

\section{Referências}

1. Jantscheff P, Terraciano L, Lowy A, Glatz-Krieger K, Grunert F, Micheel $B$ et al. Expression of CEACAM6 in resectable colorectal cancer: a factor of independent prognostic significance. J Clin Oncol. 2003;21(19):3638-46.

2. Instituto Nacional de Câncer. Coordenação de Prevenção e Vigilância de Câncer: Estimativas 2008: incidência de câncer no Brasil. Disponível em: http://www.inca.gov.br. Acessado em 14 de maio de 2010.

3. Levy M, Visokai V, Lipska L, Topolcan 0. Tumor markers in staging and prognosis of colorectal carcinoma. Neoplasma. 2008;55(2):138-42.

4. Ponz De Leon M, Sant M, Micheli A, Sacchetti C, Di Gregorio C, Fante R et al. Clinical and pathologic prognostic indicators in colorectal cancer. A population-based study. Cancer. 1992;69(3):626-35.

5. Koprowski H, Steplewski Z, Mitchell K, Herlyn M, Herlyn D, Fuhrer P. Colorectal carcinoma antigens detected by hybridoma antibodies. Somatic Cell Genet. 1979;5(6):957-72.

6. Nakagoe T, Sawai T, Tsuji T, Jibiki M, Nanashima A, Yamaguchi $H$ et al. Circulating sialyl Lewis(x), sialyl Lewis(a), and sialyl Tn antigens in colorectal cancer patients: multivariate analysis of predictive factors for serum antigen levels. J Gastroenterol. 2001;36(3):166-72.

7. Carpelan-Holmström $M$, Louhimo J, Stenman UH, Alfthan $H$, Järvinen $H$, 
Haglund C. Estimating the probability of cancer with several tumor markers in patients with colorectal disease. Oncology. 2004;66(4):296-302.

8. Salces I, Vegh I, Rodriguez-Muñoz S, Colina F, Pérez A, Soto S et al. Tissue CA19-9 content in colorectal adenomas and its value in the assessment of dysplasia. Rev Esp Enferm Dig. 2004;96(4):246-54.

9. Morales-Gutiérrez C, Vegh I, Colina F, Gómez-Cámara A, Landa IJ, Ballesteros D et al. Survival of patients with colorectal carcinoma: possible prognostic value of tissular carbohydrate antigen 19.9 determination. Cancer. 1999;86(9):1675-81.

10. Nakagoe T, Sawai T, Tsuji T, Jibiki MA, Nanashima A, Yamaguchi T et al. Difference in prognostic value between sialyl Lewis(a) and sialyl Lewis $(\mathrm{x})$ antigen levels in the preoperative serum of gastric cancer patients. J Clin Gastroenterol. 2002;34(4):408-15.

11. Shimono R, Mori M, Akazawa K, Adachi Y, Sgimachi K. Immunohistochemical expression of carbohydrate antigen 19-9 in colorectal carcinoma. Am J Gastroenterol. 1994;89(1):101-5

12. Fischbach W, Mössner J. Tissue concentrations of CEA and CA 19-9 in the carcinogenesis of colorectal carcinoma exemplified by the adenomacarcinoma sequence. Res Exp Med. 1988;188(2):101-14.

13. Asai S, Watanabe T, Sakamoto J, Kiriyama K, Ito K, Akiyama S et al. Expression and prognostic indicators of type 1 and type 2 Lewis blood group antigens in colorectal cancers. Nippon Geka Gakkai Zasshi. 1994;95(10):753-62.

14. Franchi F, Pastore C, Izzo P, Calió E. CA19-9 in the monitoring of colorectal cancer after surgery. Med Oncol. 2001;18(3):237-8.

15. Nakayama T, Watanabe M, Teramoto T, Kitajima M. CA19-9 as a predictor of recurrence in patients with colorectal cancer. J Surg Oncol. 1997;66(4):238-43

16. Wang WS, Lin JK, Chiou TJ, Liu JH, Fan FS, Yen CC et al. CA 19-9 as the most significant prognostic indicator of metastatic colorectal cancer Hepatogastroenterology. 2002;49(43):160-4.

17. Matsui T, Kojima H, Susuki H, Hamajima H, Nakazato H, Ito K et al. Sialy Lewis $^{\text {a }}$ expression as a predictor of the prognosis of colon carcinoma patients in a prospective randomized clinical Trial. Jpn J Clin Oncol. 2004;34(10):588-93.

18. Morita S, Nomura T, Fukushima Y, Morimoto T, Hiraoka N, Shibata N. Does serum CA19-9 play a practical role in the management of patients with colorectal cancer? Dis Colon Rectum. 2004;47(2):227-32.

19. Sasaki A, Kawano K, Inomata M, Shibata K, Matsumoto T, Kitano S Value of serum carbohydrate antigen 19-9 for predicting extrahepatic metastasis in patients with liver metastasis from colorectal carcinoma. Hepatogastroenterology. 2005;52(66):1814-9.
20. Nozoe T, Rikimaru T, Mori E, Okuyama T, Takahashi I. Increase in both CEA and CA19-9 in sera is an independent prognostic indicator in colorectal carcinoma. J Surg Oncol. 2006;94(2):132-7.

21. Wittekind C, Compton CC, Greene FL, Sobin LH. TNM residual tumor classification revisited. Cancer. 2002;94(9):2511-6.

22. Tempero MA, Uchida E, Takasaki H, Burnett Da, Steplewski Z, Pour PM Relationship of carbohydrate antigen 19-9 and Lewis antigens in pancreatic cancer. Cancer Res. 1987:47(20):5501-3.

23. Ueda T, Shimada E, Urakawa T. The clinicopathologic features of serum CA 19-9-positive colorectal cancers. Surg Today. 1994;24(6):518-25.

24. Nakayama T, Watanabe M, Teramoto T, Kitajima M. Slope analysis CA19-9 and CEA for predicting recurrence in colorectal cancer patients. Anticancer Res. 1997;17(2B):1379-82

25. Bast RC, Ravdin P, Hayes DF, Bates S, Fritsche H, Jessup JM et al. 2000 update of recommendations for the use of tumor markers in breast and colorectal cancer: clinical practice guidelines of the American Society of Clinical Oncology. J Clin Oncol. 2001;19(6):1865-78.

26. Chen CC, Yang SH, Lin JK, Lin TC, Chen WS, Jiang JK et al. Is it reasonable to add preoperative serum level of CEA and CA19-9 to staging for colorectal cancer? J Surg Res. 2005;124(2):169-74.

27. Duffy MJ, Van Dalen A, Haglund C, Hansson L, Holinski-Feder E, Klapdor $\mathrm{R}$ et al. Tumour markers in colorectal cancer: European Group on Tumour Markers (EGTM) guidelines for clinical use. Eur $\mathrm{J}$ Cancer. 2007;43(9):1348-60.

28. Akamine S, Nakagoe T, Sawai T, Tsuji T, Tanaka K, Hidaka S et al. Differences in prognosis of colorectal cancer patients based on the expression of sialyl Lewis ${ }^{\mathrm{a}}$, sialyl Lewis ${ }^{\mathrm{x}}$, and sialyl Lewis ${ }^{\mathrm{Tn}}$ antigens in serum and tumor tissue. Anticancer Res. 2004;24(4):2541-6.

29. Nakagoe T, Fukushima K, Nanashima A, Sawai T, Tsuji T, Jibiki M et al. Expression of Lewis(a), sialyl Lewis(a), Lewis( $\mathrm{x})$ and sialyl Lewis(x) antigens as prognostic factors in patients with colorectal cancer. Can $J$ Gastroenterol. 2000;14(9):753-60.

30. Zheng CX, Zhan WH, Zhao JZ, Zheng D, Wang DP, He YL et al. The prognostic value of preoperative serum levels of CEA, CA19-9 and CA72-4 in patients with colorectal cancer. World J Gastroenterol. 2001;7(3):431-4.

31. Takada A, Ohmori K, Yoneda T, Tsuyuoka K, Hasegawa A, Kiso M et al. Contribution of carbohydrate antigens sialyl Lewis $A$ and sialyl Lewis $X$ to adhesion of human cancer cells to vascular endothelium. Cancer Res. 1993;53(2): 354-61.

32. Hayes DF, Bast RC, Desch CE, Fritsche H Jr, Kemeny NE, Jessup JM et al. Tumor marker utility grading system: a framework to evaluate clinical utility of tumor markers. J Natl Cancer Inst. 1996;88(20):1456-66. 